\title{
Morin, a flavonoid from Moraceae, suppresses growth and invasion of the highly metastatic breast cancer cell line MDA-MB-231 partly through suppression of the Akt pathway
}

\author{
HANA JIN ${ }^{1}$, WON SUP LEE ${ }^{2}$, SO YOUNG EUN ${ }^{1}$, JI HYUN JUNG ${ }^{2}$, HYEON-SOO PARK ${ }^{5}$, \\ GONSUP KIM $^{5}$, YUNG HYUN CHOI ${ }^{8}$, CHUNG HO RYU ${ }^{6}$, JIN MYUNG JUNG ${ }^{3}$, \\ SOON CHAN HONG ${ }^{4}$, SUNG CHUL SHIN ${ }^{7}$ and HYE JUNG KIM ${ }^{1}$
}

\begin{abstract}
Departments of ${ }^{1}$ Pharmacology, ${ }^{2}$ Internal Medicine, ${ }^{3}$ Neurosurgery, and ${ }^{4}$ Surgery, Institute of Health Sciences, Gyeongsang National University School of Medicine, Jinju 660-702; ${ }^{5}$ Institute of Life Science and School of Veterinary Medicine, ${ }^{6}$ Division of Applied Life Science (BK 21 Program), and ${ }^{7}$ Department of Chemistry, Research Institute of Life Science, Gyeongsang National University, Jinju 660-701; ${ }^{8}$ Department of Biochemistry,

Dongeui University College of Oriental Medicine and Department of Biomaterial Control (BK21 program), Dongeui University Graduate School, Busan 614-052, Republic of Korea
\end{abstract}

Received May 7, 2014; Accepted June 17, 2014

DOI: 10.3892/ijo.2014.2535

\begin{abstract}
Morin, a flavonoid found in figs and other Moraceae, displays a variety of biological actions, such as anti-oxidant, anti-inflammatory and anti-carcinogenic. However, the anticancer effects of morin and in particular its anti-metastatic effects are not well known. Therefore, in the present study, we investigated the anticancer effects of morin on highly metastatic human breast cancer cells. Our results showed that morin significantly inhibited the colony forming ability of highly metastatic MDA-MB-231 breast cancer cells from low
\end{abstract}

Correspondence to: Professor Hye Jung Kim, Department of Pharmacology, Institute of Health Sciences, Gyeongsang National University School of Medicine, Jinju 660-702, Republic of Korea E-mail: hyejungkim@gnu.ac.kr

Professor Won Sup Lee, Department of Internal Medicine, Institute of Health Sciences, Gyeongsang National University School of Medicine, Jinju 660-702, Republic of Korea

E-mail: lwshmo@hanmail.net

E-mail:1wshmo@gnu.ac.kr

Abbreviations: DAPI, 4',6-diamidino-2-phenyindole, dilactate; ECM, extracellular matrix; EMT, epithelial-to-mesenchymal transition; ER, estrogen receptor; HER, human epithelial growth factor receptor; MMP, metalloproteinase; MTT, 3-(4,5-dimethylthiazole2-yl)-2,5-biphenyl tetrazolium bromide; PR, progesterone receptor; SEM, standard error; SDS-PAGE, sodium dodecyl sulfate-polyacrylamide gel electrophoresis; TBS, Tris-buffered saline; TNBC, triple-negative breast cancer; TNF, tumor necrosis factor

Key words: Akt pathway, breast cancer, invasion, morin, N-cadherin doses $(50 \mu \mathrm{M})$ without cytotoxicity. In addition, morin changed MDA-MB-231 cell morphology from mesenchymal shape to epithelial shape and inhibited the invasion of MDA-MB-231 cells in a dose-dependent manner. Morin decreased matrix metalloproteinase-9 (MMP-9) secretion and expression of the mesenchymal marker N-cadherin of MDA-MB-231 cells, suggesting that morin might suppress the EMT process. Furthermore, morin significantly decreased the phosphorylation of Akt, and inhibition of the Akt pathway significantly reduced MDA-MB-231 invasion. In an in vivo xenograft mouse model, morin suppressed MDA-MB-231 cancer cell progression. Taken together, our findings suggest that morin exhibits an inhibitory effect on the cancer progression and EMT process of highly metastatic breast cancer cells at least in part through inhibiting Akt activation. This study provides evidence that morin may have anticancer effects against metastatic breast cancer.

\section{Introduction}

Cancer is one of the leading causes of death. Breast cancer is the most common cancer diagnosed in North American and Western European women (1,2), and Asian populations generally have the lowest risk, but rates in this population have been steadily increasing. Particularly, in Korea, the incidence of breast cancer has increased 4-fold from 1996 to 2010, showing the highest growth rate of breast cancer among OECD countries (3). Majority of primary breast cancers (70-80\%) are estrogen receptor (ER)-positive (+), and $\mathrm{ER}^{+}$breast cancers generally have a better prognosis and are responsive to antiestrogen therapy. In contrast, ER-independent (ER') breast cancers including refractory cancer to antiestrogen therapy are more aggressive, possess high metastatic potential $(4,5)$. Most of these patients eventually die of metastatic disease. 
Increasing evidence shows that breast cancer cells undergo an epithelial-to-mesenchymal transition (EMT) to metastasize, and this process is frequently observed in the most aggressive subtype, estrogen receptor-negative $\left(\mathrm{ER}^{-}\right) /$progesterone receptor (PR)-negative $\left(\mathrm{PR}^{-}\right) /$human epithelial growth factor receptor 2-negative (HER2-) triple-negative breast cancer (TNBC) (6).

Numerous materials isolated from plants are being investigated for their therapeutic application against cancer metastasis. Among compounds of known structure, flavonoids deserve special attention because they are present in practically all dietary plants, fruits and root. The flavonoids, including morin $(7,8)$, are non-toxic $(9,10)$ and display a variety of biological actions including anti-carcinogenic (11-13). Mulberry trees are widely cultivated in East Asia and the white mulberry, Morus alba L. is a rich source of many bioactive phytochemicals. Five phenolic constituents, including maclurin, rutin, isoquercitrin, resveratrol and morin, have been identified in ethanolic extract of mulberry twigs to account for its potential oxidation capability; among them, maclurin and morin have been shown to be superior to the others (14).

Morin (3,5,7,2',4'-pentahydroxyflavone) is a kind of flavonoid found in figs and other Moraceae which are used as herbal medicines. It has certain biological activities, including anti-oxidant properties $(15,16)$ and anti-inflammatory effects $(17,18)$. Morin also acts as an anti-mutagen $(19,20)$ and has an anti-promotion activity in a liver carcinogenesis model (21). Most of all, the favorable safety profile of this natural compound (8) makes it a potential candidate worthy of further investigations. Such beneficial effects of morin could be expected to work in in vitro and in vivo cancer model. However, the effect of morin on cancer growth and metastasis is not well known. Therefore, in the present study, we aimed to investigate the effect of morin on the cancer growth and invasion in highly metastatic human breast cancer cells MDA-MB-231. As mentioned above, most lethal and aggressive subtype of breast cancer is $\mathrm{ER}^{-} / \mathrm{PR}^{-} / \mathrm{HER} 2^{-} \mathrm{TNBC}$ and MDA-MB-231 is a well-known TNBC. Thus, MDA-MB-231 was used in this study.

\section{Materials and methods}

Materials. Morin (Fig. 1A) was obtained from Aging Tissue Bank (Pusan, Korea). Antibodies against N-cadherin, phosphoAkt, Akt, phospho-GSK3 $\beta$ and GSK3 $\beta$ were purchased from Santa Cruz Biotechnology (Santa Cruz, CA, USA). 3-(4,5-dimethylthiazol-2-yl)-2,5-biphenyl tetrazolium bromide (MTT), 4',6-diamidino-2-phenyindole, dilactate (DAPI) and anti- $\beta$-actin antibody were obtained from Sigma-Aldrich Co. (St. Louis, MO, USA). Recombinant human tumor necrosis factor- $\alpha$ (TNF- $\alpha$ ) was obtained from R\&D Systems (Minneapolis, MN, USA). BD Matrigel ${ }^{\mathrm{TM}}$ basement membrane matrix is supplied by BD Biosciences (San Diego, CA, USA).

Cell culture. The human breast cancer cell MDA-MB-231 was grown in RPMI-1640 supplemented with 10\% FBS, 100 IU/ml penicillin and $10 \mu \mathrm{g} / \mathrm{ml}$ streptomycin. The human umbilical endothelial cell line EA.hy 926 was grown in DMEM supplemented with $10 \% \mathrm{FBS}, 100 \mathrm{IU} / \mathrm{ml}$ penicillin and $10 \mu \mathrm{g} / \mathrm{ml}$ streptomycin. All cells were incubated in a humidified $5 \% \mathrm{CO}_{2}$ incubator.

Cell proliferation assay. Cells were seeded at $10^{4}$ cells per well in 24-well plates. After treatments, $50 \mu \mathrm{l}$ of $5 \mathrm{mg} / \mathrm{ml}$ MTT solution was added to each well and incubated for $3 \mathrm{~h}$. The supernatants were aspirated and the formazan crystals were dissolved with $200 \mu \mathrm{l}$ of $4 \mathrm{~N} \mathrm{HCl}$-isopropanol in each well. The optical density of the colored product was measured at $570 \mathrm{~nm}$, as suggested by the manufacturer, using an Infinite 200 microplate reader (Tecan Austria GmbH, Grödig, Austria).

Colony formation assay. Cells were seeded in 6-well plates at 1,000 cells/well. After serum starvation for $16 \mathrm{~h}$, the cells were treated with morin at the indicated doses in a $37^{\circ} \mathrm{C}$ cell culture incubator. After $24 \mathrm{~h}$, culture medium was discarded and changed with media every 2-3 days. After 1-2 weeks, cells were fixed and stained using crystal violet and photographed. The experiments were performed in triplicate.

Western blot analysis. Cells were washed in ice-cold PBS and lysed in PRO-PREP protein extraction solution (iNtRON Biotechnology, Seoul, Korea). The samples were centrifuged at $13,000 \mathrm{rpm}$, for $15 \mathrm{~min}$ at $4^{\circ} \mathrm{C}$. An aliquot of the whole cell lysate was subjected to sodium dodecyl sulfate-polyacrylamide gel electrophoresis (SDS-PAGE) and transferred onto polyvinylidene difluoride membrane. Membranes were blocked with $5 \%$ non-fat milk in Tris-buffered saline (TBS) containing $0.05 \%$ Tween-20 for $2 \mathrm{~h}$ at room temperature and incubated with primary antibodies at 1:1,000 in TBS containing $0.05 \%$ Tween-20 and $3 \%$ bovine serum albumin overnight at $4^{\circ} \mathrm{C}$. The membranes were then incubated with horseradish peroxidase-conjugated anti-rabbit IgG $(1: 5,000)$ antibody for $1 \mathrm{~h}$ at room temperature. After washing, the membranes were developed using the ECL reagent (Bionote, Gyeonggi-do, Korea).

Matrigel invasion assay. The upper chamber of 24-well cell culture inserts $(8-\mu \mathrm{m}$ pore size, Falcon, Franklin Lakes, NJ, USA) were washed with a serum-free medium, coated with $100 \mu \mathrm{l}$ of Matrigel $(1 \mathrm{mg} / \mathrm{ml})$ and dried for $30 \mathrm{~min}$ at $37^{\circ} \mathrm{C}$. MDA-MB-231 cells treated with morin were collected; $2 \times 10^{5}$ cells were loaded to the upper chambers filled with serum-free media, and $500 \mu$ l of RPMI media containing $10 \%$ FBS was added to the lower chambers. The invasion chambers were incubated for $24 \mathrm{~h}$ in a $37^{\circ} \mathrm{C}$ cell culture incubator. The non-invasive cells that remained on the upper surface of the insert membranes were removed by scrubbing. The cells on the lower insert membranes were stained with DAPI, and cells were counted under a fluorescence microscope. Each sample was measured in triplicate, and each experiment was repeated three times.

Gelatin zymography. Gelatin zymography was performed as described by Jin et al (22). Briefly, conditioned media were concentrated using a protein concentrator (Thermo Pierce, Rockford, IL, USA) and subjected to electrophoresis on $8 \%$ PAGE gels containing $1 \mathrm{mg} / \mathrm{ml}$ gelatin. Gels were washed twice with $2.5 \%$ Triton X-100, stained with $0.2 \%$ Coomassie Brilliant Blue and destained (50\% methanol and 10\% acetic 
A<smiles>O=c1c(O)c(-c2ccc(O)cc2O)oc2cc(O)cc(O)c12</smiles>

Structure of Morin (M.W. 302.24)
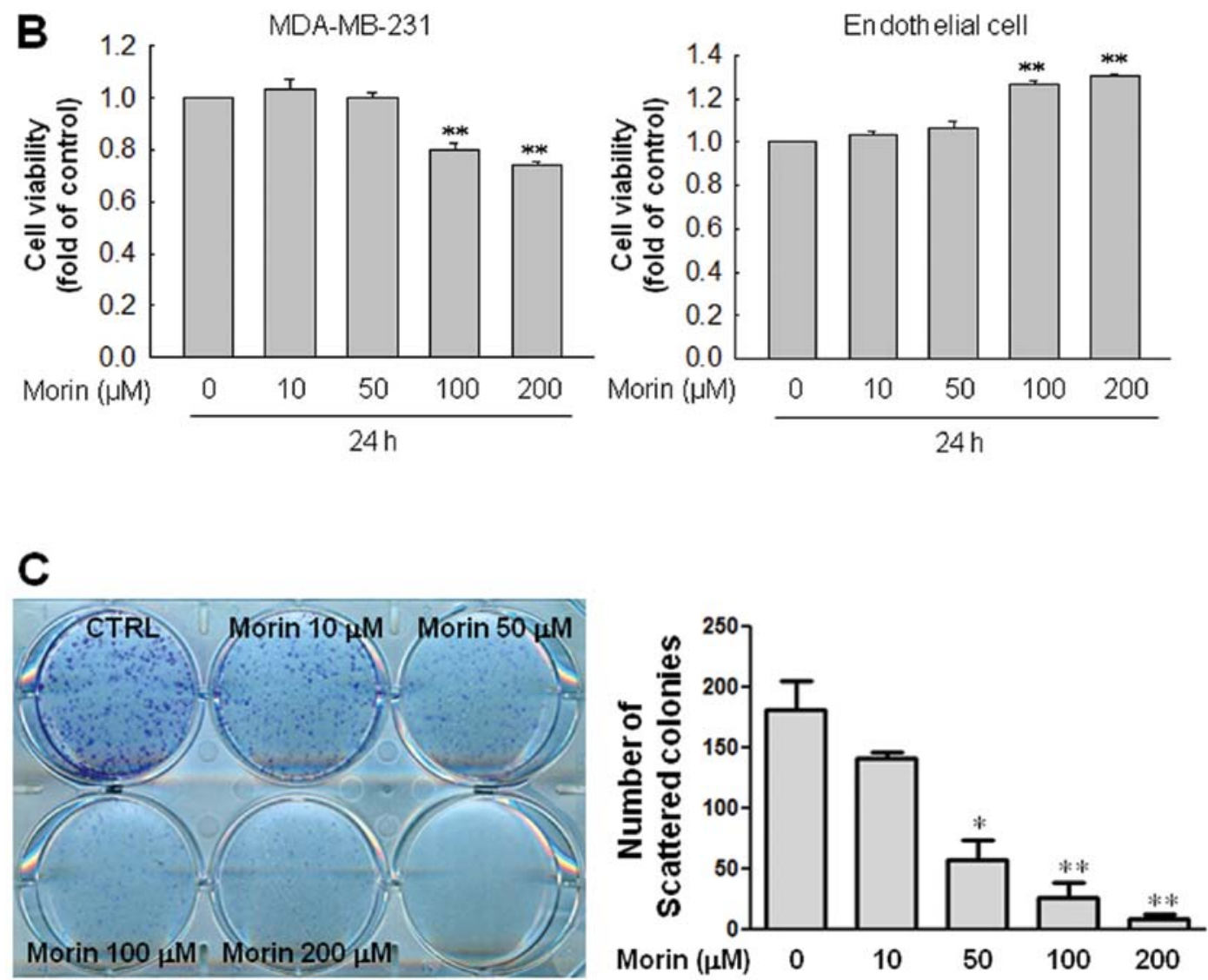

Figure 1. Morin inhibits the colony forming ability of human breast cancer MDA-MB-231 cells without cytotoxicity to human endothelial cells. (A) The structure of morin. (B) MDA-MB-231 breast cancer cells and EA.hy 926 endothelial cell were treated with the indicated concentrations of morin for 24 h. Cell viability was determined by the MTT assay. All data represent mean values \pm SEM of three independent experiments in a triplicate assay. Significance compared with control, ${ }^{* *} \mathrm{P}<0.01$. (C) MDA-MB-231 cells were seeded in 6 -well plates at 1,000 cells/well. After serum starvation, the cells were treated with morin at the indicated doses for $24 \mathrm{~h}$. Then, the cells were changed with fresh media for every 2-3 days. After 1-2 weeks, cells were fixed, stained and photographed as described in Materials and methods. The data represent mean values \pm SEM of three independent experiments in a triplicate assay. Significance compared with control, ${ }^{*} \mathrm{P}<0.05 ;{ }^{* *} \mathrm{P}<0.01$.

acid). Gelatinolytic activity was detected as clear bands in the background of blue staining.

Animal experiments. Athymic nude mice were divided into 2 groups ( 5 mice/group) and received morin at the dose of 10 and $50 \mathrm{mg} / \mathrm{kg}$ (daily, i.p.), respectively for 7 days. Mice were

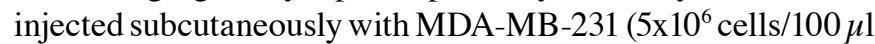
of serum-free RPMI). Tumors were allowed to grow until they reached $4 \mathrm{~mm}$. At this point, mice were divided into 2 groups (7 mice/group): control and morin-treated mice. The mice were administered a daily i.p. injection of $10 \mathrm{mg} / \mathrm{kg}$ (non-toxic dose) morin for 45 days. The mice were sacrificed at day 45 , and the tumors were extracted. Body weights and tumor volumes were measured every 3 days, starting at 7 days after injection. The experimental protocol was approved by the
Institutional Animal Care and Use Committee at Gyeongsang National University.

Statistical evaluations. Scanning densitometry was performed using Image Master ${ }^{\circledR}$ VDS (Pharmacia Biotech Inc., San Francisco, CA, USA). The treatment groups were compared using one-way analysis of variance and the post hoc test by Scheffe. $\mathrm{P}<0.05$ was considered statistically significant. All data were expressed as the mean \pm standard error (SEM).

\section{Results}

Morin inhibits the colony forming ability of the human breast cancer MDA-MB-231 cells without cytotoxicity to human endothelial cells. First, we examined the cell viability of 

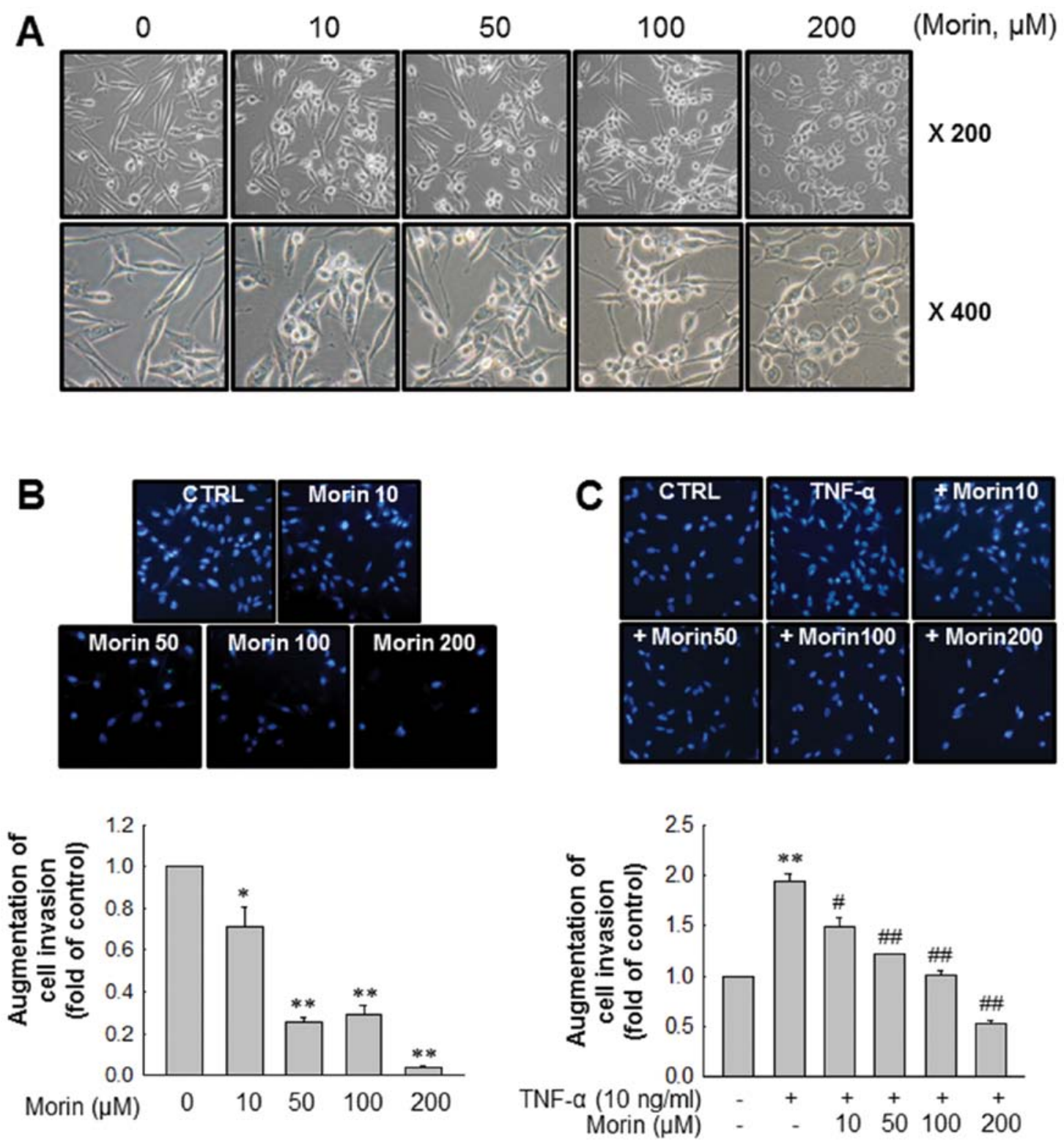

Figure 2. Morin affects cell morphology and inhibits the invasion of MDA-MB-231 breast cancer cells. (A) Cells were seeded at 5x10 4 cells/ml and were treated with morin in a dose-dependent manner. After $24 \mathrm{~h}$, the morphologic changes of cells were observed under a microscope (upper panel, $\mathrm{x} 200$; lower panel, x400). Data are representative of three independent experiments. (B and C) MDA-MB-231 were starved for $16 \mathrm{~h}$ and then pretreated with morin at the indicated concentrations for $24 \mathrm{~h}$. Cells were collected, applied in Matrigel-coated insert well and then incubated with or without TNF- $\alpha$ (10 ng/ml) for $24 \mathrm{~h}$ at $37^{\circ} \mathrm{C}$. The non-invasive cells that remained on the upper side of the insert were removed, and the cells on the lower part of insert membranes were stained with DAPI. The number of cells that invaded through the membrane was quantified by counting cells under a fluorescence microscope. Images from three randomly selected fields are presented. Values are the means \pm SEM from three independent determinations. Significance compared with control, ${ }^{*} \mathrm{P}<0.05,{ }^{* *} \mathrm{P}<0.01$; significance compared to TNF- $\alpha,{ }^{\#} \mathrm{P}<0.05,{ }^{\# \#} \mathrm{P}<0.01$.

MDA-MB-231 cells and normal endothelial cells in response to morin. When MDA-MB-231 cells and endothelial cells were treated with indicated doses of morin $(10,50,100$ and $200 \mu \mathrm{M}$ ) for $24 \mathrm{~h}$, the results revealed that morin did not affect cell viability at the doses $<100 \mu \mathrm{M}$ both in MDA-MB-231 cells and endothelial cells. High concentrations (100 and $200 \mu \mathrm{M})$ of morin reduced cell viability of MDA-MB-231 a little but rather increased cell viability in endothelial cells (Fig. 1B). Thus, we investigated the effect of morin on the ability of MDA-MB-231 cells to form colonies. Interestingly, morin effectively inhibited colony formation of MDA-MB-231 cells in a dose-dependent manner (Fig. 1C).
Morin affects cell morphology and inhibits the invasion of MDA-MB-231 breast cancer cells. Next, we observed changes of MDA-MB-231 cells in morphology after morin treatment. As shown in Fig. 2A, morin induced morphologic changes of MDA-MB-231 cells from mesenchymal form to epithelial form in a dose-dependent manner. We then determined the effects of morin on MDA-MB-231 cell invasion because cancer cell invasion is the first step for cancer metastasis. Matrigel invasion assays revealed that morin significantly inhibited cell invasion in a dose-dependent manner (Fig. 2B). Moreover, morin also effectively inhibited TNF- $\alpha$-induced MDA-MB-231 cell invasion in a similar manner (Fig. 2C). 
A
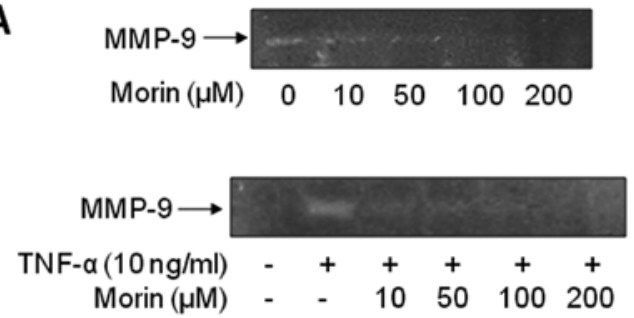

B
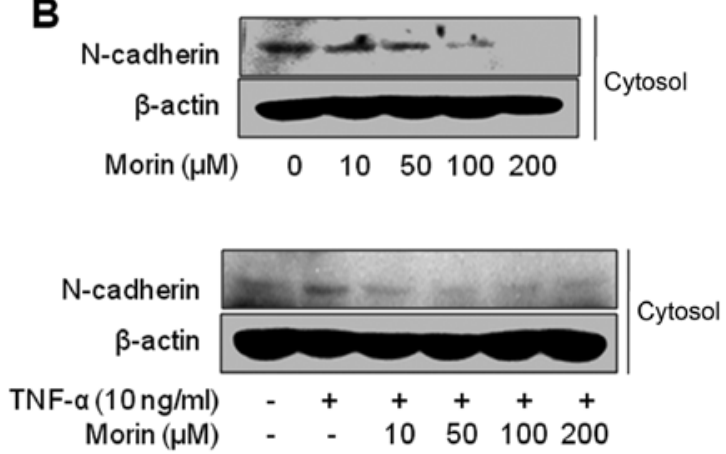

Figure 3. Morin downregulates MMP-9 secretion and the mesenchymal marker N-cadherin. MDA-MB-231 were starved for $16 \mathrm{~h}$ and then pretreated with morin at the indicated concentrations for $24 \mathrm{~h}$. Then, the cells were stimulated with TNF- $\alpha(10 \mathrm{ng} / \mathrm{ml})$ or not for additional $24 \mathrm{~h}$. (A) After the treatment, the media were collected for the determination of gelatinolytic activity of MMP-9 by gelatin zymography as described in Materials and methods. (B) Cells were collected, and N-cadherin levels in cytosolic fractions were determined by western blot analysis. Data were confirmed by two independent experiments.
Morin decreases matrix metalloproteinase-9 (MMP-9) secretion and the mesenchymal marker $N$-cadherin expression involved in cancer metastasis. Proteolytic digestion of the extracellular matrix (ECM) by secreted MMPs is one of major steps for cancer invasion $(23,24)$. MMP-2, -3 and -9 are also biomarkers for EMT (25). In particular, MMP-9 expression is associated with pathological processes, including inflammation, atherosclerosis and tumor-cell invasion and metastasis (26-28). Thus, we examined the effect of morin on the activity of the secreted MMP-9 from MDA-MB-231 cells in the presence of TNF- $\alpha$ or not by gelatin zymographic analysis. Morin dose-dependently suppressed the gelatinolytic activities of secreted MMP-9 in MDA-MB-231 cells. MMP-9 secretion augmented by TNF- $\alpha$ was also significantly inhibited by a low dose of morin $(10 \mu \mathrm{M})$ (Fig. 3A). In addition, we also assessed the changes in EMT biomarkers to confirm that morin has inhibitory effects on EMT. Fig. 3B showed that morin inhibited mesenchymal markers $\mathrm{N}$-cadherin, but did not influence the expressions of either vimentin or E-cadherin of MDA-MB-231 cells (data not shown). These results suggest that morin might suppress the invasion of highly metastatic MDA-MB-231 breast cancer cells through regulating the EMT process.

Morin inhibits the invasion of MDA-MB-231 breast cancer cells through inhibiting Akt pathway but not GSK3 $\beta$ pathway. Concerning the upstream signals that affect $\mathrm{N}$-cadherin, $\beta$-catenin induces $\mathrm{N}$-cadherin expression, and $\beta$-catenin is negatively regulated by GSK-3 $\beta$. GSK- $3 \beta$ is regulated by intracellular signaling pathways including PI3K/Akt. In other
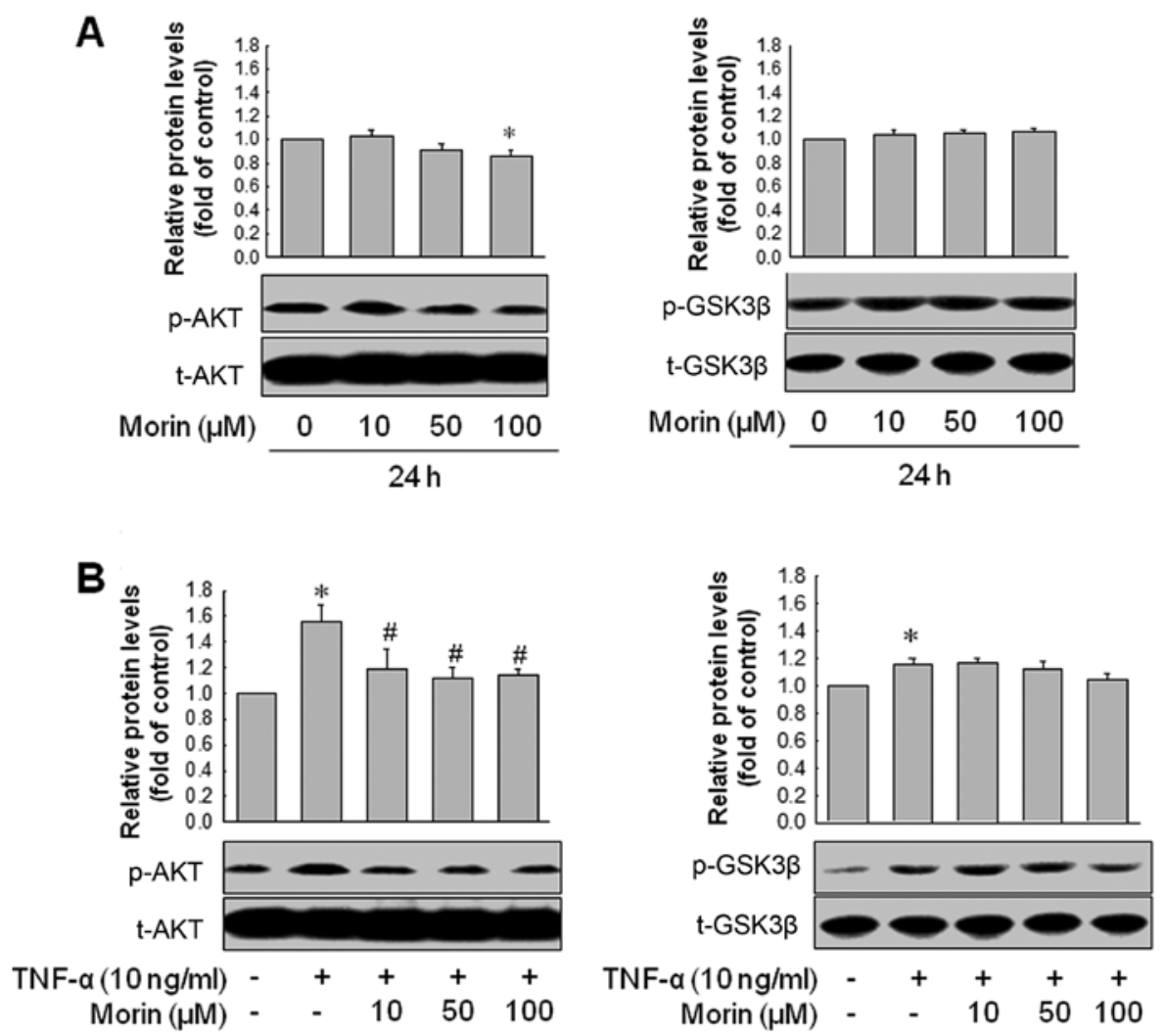

Figure 4. Morin inhibits Akt phosphorylation in MDA-MB-231 breast cancer cells. Cells were pretreated with morin at the indicated concentrations for $24 \mathrm{~h}(\mathrm{~A})$, and then treated with TNF- $\alpha$ or not for $30 \mathrm{~min}$ for detection of phospho-Akt or phospho-GSK3 $\beta$ (B). For reference, total Akt and GSK3 $\beta$ blots are used. Cells were extracted and protein level was detected by western blot analysis. Values are the means \pm SEM from three independent determinations. Significance compared with control, ${ }^{*} \mathrm{P}<0.05$; significance compared to TNF- $\alpha,{ }^{\#} \mathrm{P}<0.05$. 

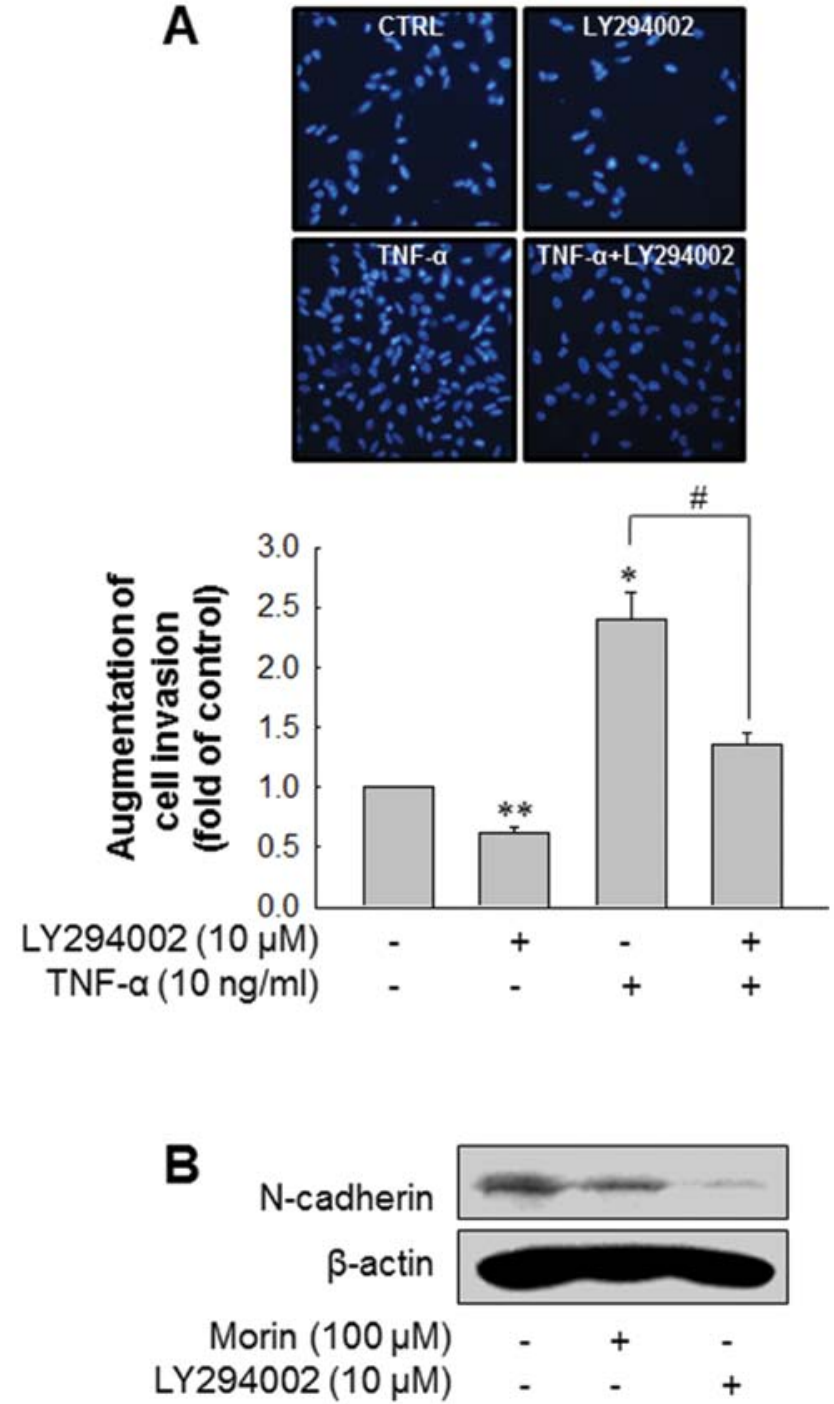

Figure 5. Morin inhibits the invasion of MDA-MB-231 breast cancer cells through inhibiting Akt pathway-N-cadherin level. (A) Cells were seeded on the Matrigel-coated insert well and were pretreated with LY294002, an inhibitor of PI3K/Akt pathway, for $1 \mathrm{~h}$. Then, cells were stimulated with TNF- $\alpha(10 \mathrm{ng} / \mathrm{ml})$ for $24 \mathrm{~h}$ at $37^{\circ} \mathrm{C}$. The non-invasive cells that remained on the upper side of the insert were removed, and the cells on the lower part of insert membranes were stained with DAPI and counted under a fluorescence microscope as described in the Fig. 2B and C. Values represent the means \pm SEM of 3 independent experiments. Significance compared with control, ${ }^{*} \mathrm{P}<0.05,{ }^{* * *} \mathrm{P}<0.01$; significance compared to TNF- $\alpha,{ }^{\prime \prime} \mathrm{P}<0.05$. (B) Cells were pretreated with LY294002 and then stimulated with TNF- $\alpha(10 \mathrm{ng} / \mathrm{ml})$ as described above. After $24 \mathrm{~h}$, cells were extracted, and $\mathrm{N}$-cadherin levels in cytosolic fractions were detected by western blot analysis. Results were confirmed by repeated experiments.

words, activation of PI3K/Akt results in the phosphorylation of GSK-3 $\beta$ (inactivation of GSK-3 $\beta$ ), which in turn increases $\beta$-catenin protein levels. Thus, we investigated whether morin modulates Akt and GSK-3 $\beta$ pathways in MDA-MB-231. Morin reduced phosphorylated Akt level in MDA-MB-231 cells but failed to inhibit GSK-3 $\beta$ phosphorylation. In addition, TNF- $\alpha$ (10 ng/ml) enhanced Akt phosphorylation in MDA-MB-231, which was also significantly inhibited by morin. Morin did not reduce the TNF- $\alpha$-mediated phosphorylation of GSK-3 $\beta$ (Fig. 4A and B). Then, we confirmed whether inhibition of Akt pathway could block the invasion of MDA-MB-231. As expected, inhibition of Akt pathway using LY294002 significantly decreased the invasion of MDA-MB-231 as well as TNF- $\alpha$-enhanced invasion of MDA-MB-231 (Fig. 5A). In addition, LY294002 downregulated N-cadherin expression level (Fig. 5B). These results suggest that morin suppresses the invasion of MDA-MB-231 breast cancer cell through inhibiting Akt pathway and $\mathrm{N}$-cadherin expression.

Morin reduces breast cancer cell growth in xenograft mouse model in vivo. To confirm the in vivo effect of morin in tumor progression, morin was injected into tumor-bearing mice for 45 days. Before that, to determine whether morin has a toxic effect in vivo, the mice received i.p. a daily injection of 10 or $50 \mathrm{mg} / \mathrm{kg}$ morin for 7 days (n=7/group). Both 10 and $50 \mathrm{mg} / \mathrm{kg}$ concentrations of morin caused no lethality in mice (Fig. 6A), however $50 \mathrm{mg} / \mathrm{kg}$ made the mice somewhat nervous. Thus, we used $10 \mathrm{mg} / \mathrm{kg}$ of morin for further experiments. Control animals developed significant tumor growth during the 45-day follow-up period, as shown by the tumor volume in Fig. 6B and $\mathrm{C}$. In contrast, animals that received $10 \mathrm{mg} / \mathrm{kg}$ morin daily showed that tumor growth was significantly inhibited (Fig. 6B and C). Body weight does not show any significant differences between the groups.

\section{Discussion}

Cancer metastasis is responsible for most cancer death rather than the primary tumors (29-31). Cancer metastasis is a complex process involving the coordinated responses among cancer cells, normal cells and ECM. Variable growth factors, MMPs and cytokines including TNF- $\alpha$ stimulate cancer metastasis (32-34). Considered that tumor metastasis is the main cause of mortality of cancer patients, it is more beneficial to develop drugs that are able to suppress the highly metastatic cancer cells progression. Indeed, human breast cancer cells MDA-MB-231 express putative aggressiveness markers and are well known as an ER/PR/HER2- TNBC. Therefore, in this study, we examined the anticancer effect of morin using the highly metastatic human breast cancer cells MDA-MB-231. Our results showed that morin significantly inhibited the ability of MDA-MB-231 cells to form colony and invade. In addition, morin suppressed the EMT process. Interestingly, morin has no severe cytotoxicity to cancer cells or normal endothelial cells; high concentrations (100 and $200 \mu \mathrm{M}$ ) of morin slightly reduced cell viability of MDA-MB-231 but rather increased cell viability in endothelial cells. These results suggest that morin could be used in cancer patients without serious cytotoxicity. Previous studies demonstrated that natural compounds could safely induce anticancer effects.

A family of extracellular matrix-degrading enzymes, the MMPs, has been implicated in inflammation and cancer (35). In particular, MMP-9 expression is associated with pathological processes, including inflammation, atherosclerosis and tumor cell invasion and metastasis (26-28). Increased levels of serum and tissue expression of MMP-9 are associated with a poor prognosis of breast cancer (36). Our results also showed that MMP-9 secretion was more prominent than MMP-2 in MDA-MB-231 (data not shown), which was effectively inhibited by morin.

For the evaluation of EMT process, it is important to assess the expression of E-cadherin an epithelial marker, but 

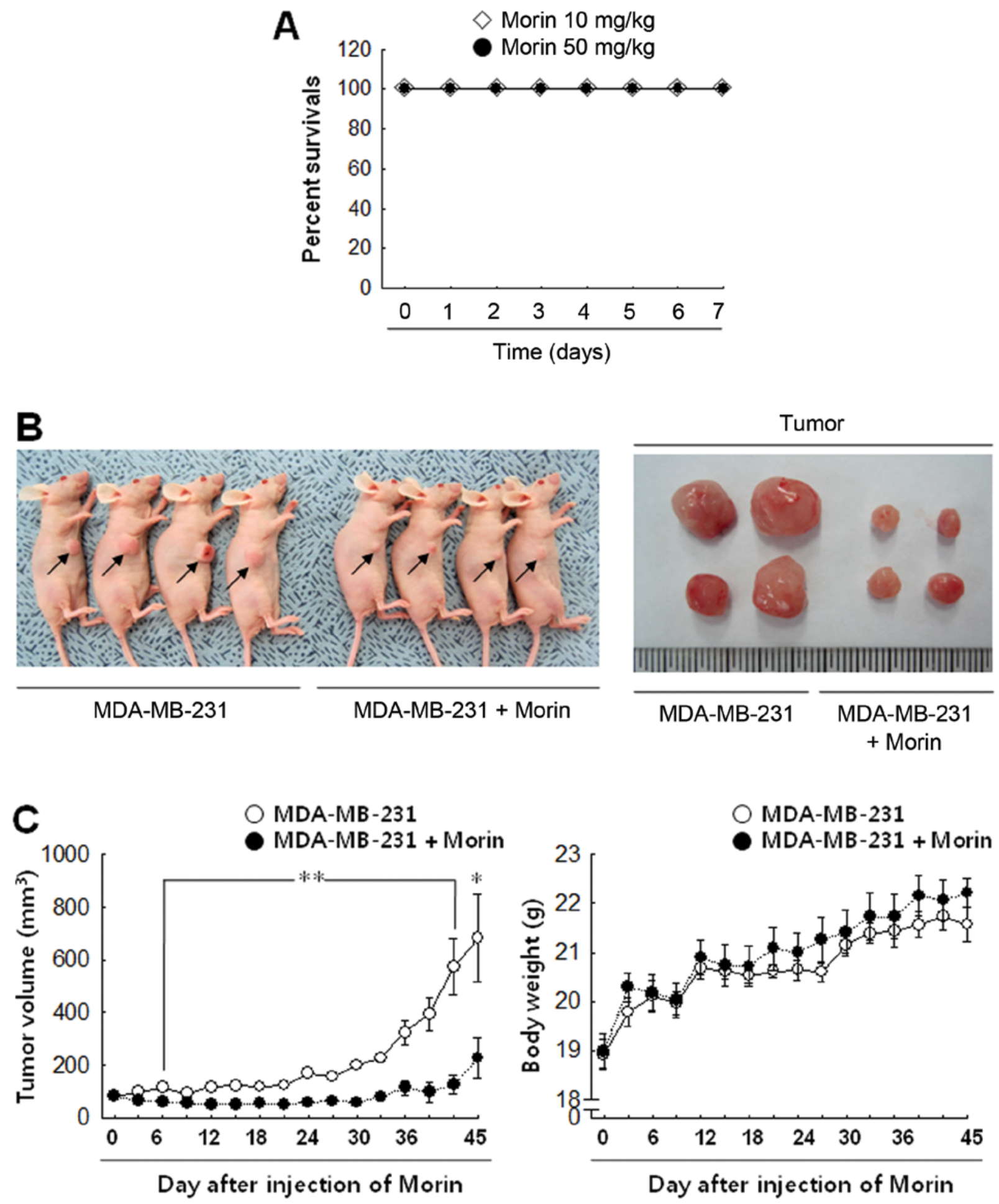

Figure 6. Morin reduces breast cancer cell growth in a mouse model in vivo (A) Survival curves of mice treated with morin $10 \mathrm{or} 50 \mathrm{mg} / \mathrm{kg}$. Athymic nude mice were divided into 2 groups ( 5 mice $/$ group): morin $10 \mathrm{mg} / \mathrm{kg}$-treated mice and morin $50 \mathrm{mg} / \mathrm{kg}$-treated ones. The mice received i.p. daily injection of

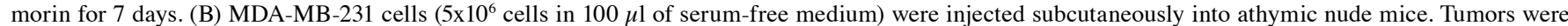
allowed to grow until they reached $4 \mathrm{~mm}$. At this point, mice were divided into 2 groups ( 7 mice/group): control and morin-treated mice. The mice received i.p. a daily injection of $10 \mathrm{mg} / \mathrm{kg}$ morin for 45 days. The mice were sacrificed at day 45 , and the tumors were extracted. (C) Tumor volumes and body weights were measured every 3 days during tumor development. Significance compared with control, ${ }^{,} \mathrm{P}<0.05,{ }^{* *} \mathrm{P}<0.01$.

E-cadherin expression level of MDA-MB-231 was too low to detect (22). Instead, we showed that morin downregulated $\mathrm{N}$-cadherin expression in the MDA-MB-231. The expression of $\mathrm{N}$-cadherin $(37,38)$ is frequently upregulated in moderatelyto-poorly invasive duct carcinomas (IDCs) $(39,40)$ and
HER2-amplified tumors. Accordingly, it is suggesting that $\mathrm{N}$-cadherin might play a role in cancer invasion and EMT in breast cancer. In this respect, morin might downregulate the EMT process by suppressing N-cadherin expression. Activation of PI3K/Akt causes an inactivation of GSK-3 $\beta$, which in turn 
increases $\beta$-catenin protein levels, and finally results in the $\mathrm{N}$-cadherin expression. Our results showed that morin significantly decreased phosphorylation of Akt in MDA-MB-231 cells as well as in TNF- $\alpha$-stimulated MDA-MB-231 cells. Inhibition of Akt pathway using LY294002, a PI3K/Akt inhibitor, significantly reduced MDA-MB-231 invasion in the presence of TNF- $\alpha$ or not, suggesting that morin suppresses EMT at least in part through suppressing Akt pathway. However, morin did not affect GSK-3 $\beta$ phosphorylation. Without GSK-3 $\beta$ phosphorylation, MMP expression and activity can regulate $\mathrm{N}$-cadherin function (41-43). In addition, gene expression of MMPs can be regulated via the Akt pathways $(44,45)$. These findings support that morin may suppress the EMT process by inhibiting MMP-9 activity followed by N-cadherin expression through suppression of Akt pathway. Furthermore, MMP-9 is also involved in EMT. Finally, we confirmed the anticancer effect of morin using in vivo xenograft mouse model in which animals were injected with MDA-MB-231 cells.

Taken together, our findings suggest that morin exhibits an inhibitory effect on the cancer progression by inhibiting EMT in the highly metastatic breast cancer MDA-MB-231 cells at least in part through inhibiting Akt activation. These findings suggest that morin may serve as an effective therapeutic strategy against metastatic breast cancer without side effects.

\section{Acknowledgements}

This study was supported by grants from the National R\&D Program for Cancer Control, Ministry of Health \& Welfare, Republic of Korea (0820050) and the National Research Foundation of Korea (NRF) funded by the Ministry of Education, Science and Technology (2012R1A1A3003268). We thank the Aging Tissue Bank (ATB) for providing research materials and information.

\section{References}

1. Hayes DF, Isaacs C and Stearns V: Prognostic factors in breast cancer: current and new predictors of metastasis. J Mammary Gland Biol Neoplasia 6: 375-392, 2001.

2. Parkin DM, Bray F, Ferlay J and Pisani P: Global cancer statistics, 2002. CA Cancer J Clin 55: 74-108, 2005.

3. Korean Breast Cancer Society: Korean breast cancer data of 1996. J Korean Surg Soc 55: 621-635, 1998.

4. Keen JC and Davidson NE: The biology of breast carcinoma. Cancer 97: 825-833, 2003.

5. Anandappa SY, Sibson R, Platt-Higgins A, Winstanley JH, Rudland PS and Barraclough R: Variant estrogen receptor $\alpha$ mRNAs in human breast cancer specimens. Int $\mathrm{J}$ Cancer 88: 209-216, 2000.

6. Mostert B, Sleijfer S, Foekens JA and Gratama JW: Circulating tumor cells (CTCs): detection methods and their clinical relevance in breast cancer. Cancer Treat Rev 35: 463-474, 2009.

7. Yugarani T, Tan BKH, The M and Das NP: Effects of polyphenolic natural products on the lipid profiles of rats fed high fat diets. Lipids 27: 181-186, 1992.

8. Wu TW, Zeng LH, Wu J and Fung KP: Morin: a wood pigment that protects three types of human cells in the cardiovascular system against oxyradical damage. Biochem Pharmacol 47: 1099-1103, 1994

9. Kleijnen J and Knipschild P: Ginkgo biloba. Lancet 340: 1136-1139, 1992

10. McGregor D: Diets, food components and human cancer. Biotherapy 11: 189-200, 1998.

11. Robak J and Gryglewski RJ: Flavonoids are scavengers of superoxide anion. Biochem Pharmacol 37: 83-88, 1998.
12. Husain SR, Cillard J and Cillard P: Hydroxyl radical scavenging activity of flavonoids. Phytochemistry 26: 2489-2492, 1987.

13. Stavric B: Role of chemopreventers in human diet. Clin Biochem 27: 319-332, 1994.

14. Chang LW, Juang LJ, Wang BS, Wang MY, Tai HM, Hung WJ, Chen YJ and Huang MH: Antioxidant and antityrosinase activity of mulberry (Morus alba L.) twigs and root bark. Food Chem Toxicol 49: 785-790, 2011

15. Ramanathan L, Das NP and Li QT: Studies on lipid oxidation in fish phospholipid liposomes. Biol Trace Elem Res 40: 59-70, 1994.

16. Hanasaki Y, Ogawaa S and Fukui S: The correlation between active oxygens scavenging and antioxidative effects of flavonoids. Free Radic Biol Med 16: 845-850, 1994.

17. Nakadate T, Yamamoto S, Aizu E and Kato R: Effects of flavonoids and antioxidants on 12-O-tetradecanoylphorbol-13acetate-caused epidermal ornithine decarboxylase induction and tumor promotion in relation to lipoxygenase inhibition by these compounds. Gann 75: 214-222, 1984.

18. Baumann J, Bruchhausen FV and Wurm G: Flavonoids and related compounds as inhibitors of arachidonic acid peroxidation. Prostaglandins 20: 627-639, 1980.

19. Francis AR, Shetty TK and Bhattacharya RK: Modulating effect of plant flavonoids on the mutagenicity of N-methyl-N'-nitroN-nitrosoguanidine. Carcinogenesis 10: 1953-1955, 1989.

20. Huang MT, Wood AW, Newmark HL, Sayer JM, Yagi H, Jerina DM and Conney AH: Inhibition of the mutagenicity of bay-region diol-epoxides of polycyclic aromatic hydrocarbons by phenolic plant flavonoids. Carcinogenesis 4: 1631-1637, 1983.

21. Denda A, Ura H, Tsujiuchi T, Tsutsumi M, Eimoto H, Takashima Y, Kitazawa S, Kinugasa T and Konishi Y: Possible involvement of arachidonic acid metabolism in phenobarbital promotion of hepatocarcinogenesis. Carcinogenesis 10: 1929-1935, 1989.

22. Jin H, Lee WS, Yun JW, Jung JH, Lee SM, Kim HJ, Choi YH, Kim GS, Jung JM, Ryu CH, Shin SC and Hong SC: Flavonoids from Citrus unshiu Marc. inhibit cancer cell adhesion to endothelial cells by selective inhibition of VCAM-1. Oncol Rep 30: 2336-2342, 2013

23. Vihinen P and Kahari VM: Matrix metalloproteinases in cancer: prognostic markers and therapeutic targets. Int $\mathbf{J}$ Cancer 99: 157-166, 2002.

24. Deryugina EI and Quigley JP: Matrix metalloproteinases and tumor metastasis. Cancer Metastasis Rev 25: 9-34, 2006.

25. Radisky ES and Radisky DC: Matrix metalloproteinase-induced epithelial-mesenchymal transition in breast cancer. J Mammary Gland Biol Neoplasia 15: 201-212, 2010.

26. Lelongt B, Trugnan G, Murphy G and Ronco PM: Matrix metalloproteinases MMP2 and MMP9 are produced in early stages of kidney morphogenesis but only MMP9 is required for renal organogenesis in vitro. J Cell Biol 136: 1363-1373, 1997.

27. Sarén P, Welgus HG and Kovanen PT: TNF-alpha and IL-1beta selectively induce expression of $92-\mathrm{kDa}$ gelatinase by human macrophages. J Immunol 157: 4159-4165, 1996.

28. Przybylowska K, Kluczna A, Zadrozny M, Krawczyk T, Kulig A, Rykala J, Kolacinska A, Morawiec Z, Drzewoski J and Blasiak J: Polymorphisms of the promoter regions of matrix metalloproteinases genes MMP-1 and MMP-9 in breast cancer. Breast Cancer Res Treat 95: 65-72, 2006.

29. Steeg PS: Cancer: micromanagement of metastasis. Nature 449: 671-673, 2007.

30. Steeg PS: Tumor metastasis: mechanistic insights and clinical challenges. Nat Med 12: 895-904, 2006.

31. Eccles SA and Welch DR: Metastasis: recent discoveries and novel treatment strategies. Lancet 369: 1742-1757, 2007.

32. White ES, Strom SR, Wys NL and Arenberg DA: Non-small cell lung cancer cells induce monocytes to increase expression of angiogenic activity. J Immunol 166: 7549-7555, 2001.

33. Ueno T, Toi M, Saji H, Muta M, Bando H, Kuroi K, Koike M, Inadera $\mathrm{H}$ and Matsushima $\mathrm{K}$ : Significance macrophage chemoattractant protein-1 in macrophage recruitment, angiogenesis, and survival in human breast cancer. Clin Cancer Res 6: 3282-3289, 2000

34. Naylor MS, Stamp GW, Davies BD and Balkwill FR: Expression and activity of MMPS and their regulators in ovarian cancer. Int J Cancer 58: 50-56, 1994.

35. Kessenbrock K, Plaks V and Werb Z: Matrix metalloproteinases: regulators of the tumor microenvironment. Cell 141: 52-67, 2010. 
36. Wu ZS, Wu Q, Yang JH, Wang HQ, Ding XD, Yang F and $\mathrm{Xu}$ XC: Prognostic significance of MMP-9 and TIMP-1 serum and tissue expression in breast cancer. Int J Cancer 122: 20502056, 2008.

37. Suyama K, Shapiro I, Guttman M and Hazan RB: A signaling pathway leading to metastasis is controlled by $\mathrm{N}$-cadherin and the FGF receptor. Cancer Cell 2: 301-314, 2002.

38. Hulit J, Suyama K, Chung S, Keren R, Agiostratidou G, Shan W, Dong X, Williams TM, Lisanti MP, Knudsen K and Hazan RB $\mathrm{N}$-cadherin signaling potentiates mammary tumor metastasis via enhanced extracellular signal-regulated kinase activation. Cancer Res 67: 3106-3116, 2007.

39. Nagi C, Guttman M, Jaffer S, Qiao R, Keren R, Triana A, Li M, Godbold J, Bleiweiss IJ and Hazan RB: N-cadherin expression in breast cancer: correlation with an aggressive histologic variant-invasive micropapillary carcinoma. Breast Cancer Res Treat 94: 225-235, 2005

40. Walsh MM and Bleiweiss IJ: Invasive micropapillary carcinoma of the breast: eighty cases of an underrecognized entity. Hum Pathol 32: 583-589, 2001
41. Ho AT, Voura EB, Soloway PD, Watson KL and Khokha R: MMP inhibitors augment fibroblast adhesion through stabilization of focal adhesion contacts and up-regulation of cadherin function. J Biol Chem 276: 40215-40224, 2001.

42. Covington MD, Burghardt RC and Parrish AR: Ischemiainduced cleavage of cadherins in NRK cells requires MT1-MMP (MMP-14). Am J Physiol Renal Physiol 290: F43-F51, 2006.

43. Pon YL, Auersperg N and Wong AS: Gonadotropins regulate $\mathrm{N}$-cadherinmediated human ovarian surface epithelial cell survival at both posttranslational and transcriptional levels through a cyclic AMP/protein kinase A pathway. J Biol Chem 280: 15438-15448, 2005.

44. Yoon SO, Shin S, Lee HJ, Chun HK and Chung AS: Isoginkgetin inhibits tumor cell invasion by regulating phosphatidylinositol 3-kinase/Akt-dependent matrix metalloproteinase-9 expression. Mol Cancer Ther 5: 2666-2675, 2006.

45. Chung TW, Lee YC and Kim CH: Hepatitis B viral HBx induces matrix metallo- proteinase-9 gene expression through activation of ERK and PI-3K/AKT pathways: involvement of invasive potential. FASEB J 18: 1123-1125, 2004. 